\title{
Light-Dependent Oxidative Stress Determines Physiological Leaf Spot Formation in Barley
}

\author{
Yue-Xuan Wu and Andreas von Tiedemann
}

First author: Laboratory of Cell Biology, National Heart, Lung and Blood Institute, National Institutes of Health, 9000 Rockville Pike, Bethesda, MD 20892; and second author: Institute of Plant Pathology and Plant Protection, Georg-August University Göttingen, Grisebachstrasse 6, 37077 Göttingen, Germany. Accepted for publication 15 January 2004.

\begin{abstract}
Wu, Y.-X., and von Tiedemann, A. 2004. Light-dependent oxidative stress determines physiological leaf spot formation in barley. Phytopathology 94:584-592.

We reported previously that physiological leaf spot (PLS) formation in winter and spring barley is dependent on genotype-related oxidative stress under field conditions. In the present study, we searched for factors inducing PLS symptoms in the greenhouse similar to those observed in the field and investigated its relationship to reactive oxygen species (ROS) metabolism. We found that in the greenhouse, oxidative stress induced spring barley cv. Extract, which is sensitive to PLS, to express symptoms similar to those observed in the field. Leaves severely affected by PLS showed significantly lower activities of key enzymes in the HalliwellAsada cycle such as ascorbate peroxidase, glutathione reductase, dehydroascorbate reductase, and monodehydroascorbate reductase. The sensitive cultivar also showed lower levels of total superoxide dismutase

ROS metabolism in chloroplasts may trigger PLS incidence in sensitive cultivars, which is in agreement with the fact that light is essential for the induction of PLS expression under both field and greenhouse conditions. Accordingly, under greenhouse conditions, continuous light stress (7 days), but not light shock treatments, induced PLS similar to that of field conditions in sensitive cv. Extract, but not in resistant cv. Scarlett. Light with a high proportion of energy in the blue wavelength spectrum (350 to $560 \mathrm{~nm}$ ) was significantly more PLS inductive than light with a pronounced red (photosynthetically active radiation) spectrum (580 to $650 \mathrm{~nm}$ ). Exposure to ozone did not produce PLS-like symptoms. Furthermore, similar to earlier observations in the field, PLS symptom expression was closely correlated with the accumulation of superoxide $\left(\mathrm{O}_{2}{ }^{-}\right)$detected by both biochemical and histochemical assays. Taken together, these data suggest that PLS in barley is genotype-dependent but its expression appears to be induced by certain environmental stress factors, among which photosynthetically active radiation plays a major role.
\end{abstract} (SOD) and $\mathrm{Cu} / \mathrm{Zn}$-SOD activity but a higher level of chloroplast-specific Fe-SOD activity than that of the insensitive cultivar. Thus, an unbalanced
Additional keyword: antioxidant enzymes.
A leaf spot disease on barley, denoted physiological leaf spots (PLS), with unknown etiology, has been observed since the late 1980 s in Germany and has become significantly more pronounced in recent years. Similar leaf spots in barley have been reported from other European countries, North America, and Australia $(3,14,30,31)$. Several studies on this type of leaf spots so far showed that microbial pathogens are not involved (29), leaving the causal agent of this leaf spot disease largely unclear.

Necrotic symptoms on barley can be caused by either various pathogens or environmental stresses. The former may be fungi, bacteria, viruses, or phytoplasmas. The latter may consist of high levels of irradiation, extreme temperature, improper use of agrochemicals, nutrient deficiency or toxicity, or air pollutants, which may cause nonspecific cell death, also named nonparasitic necrosis $(8,13,19,35)$. However, the nonparasitic necrosis symptoms are sometimes too indistinct and closely resemble those caused by pathogens, thus rendering the diagnosis of such noninfectious disease difficult. Proof of etiology of nonparasitic diseases requires both demonstrating the absence of any pathogens and reproducing the specific symptoms on healthy plants by subjecting them to conditions similar to those thought to cause the symptoms in the field. To date, despite the focus by many groups on the etiology of PLS, reproduction of similar symptoms under artificial stresses remains elusive.

Corresponding author: A. von Tiedemann; E-mail address: atiedem@gwdg.de

Publication no. P-2004-0423-01R

(C) 2004 The American Phytopathological Society
The etiology of nonparasitic necrosis appears very complicated and little is known about the primary physiological and biochemical events associated with its induction in various plant species or organs. The development of chlorosis and necrosis of potato leaves induced by constant-light treatment is associated with the loss of photosynthetic competence, starch content, and chloroplast membrane integrity, which appears to resemble the process of senescence. These symptoms are probably secondary events, induced by some unidentified primary events (8).

PLS symptom expression varies in kind and severity depending on cultivars, regions, and weather conditions $(26,34)$. We previously reported that PLS occurring on winter and spring barley may be a genotype-environment interaction related to oxidative stress (36). In order to test this hypothesis, we examined the visible symptom development and biochemical responses of different genotypes of spring barley, differing in susceptibility to PLS, under various artificial stress conditions including ozone exposure, light intensity changes, continuous light, and specific light wavelengths.

\section{MATERIALS AND METHODS}

Field sampling. PLS scoring and leaf sampling were done in the cultivar evaluation experiment conducted by the State Experimental Station for Agriculture in Biestow, near Rostock, northeastern Germany, from 1999 to 2000. The experiment was arranged in a randomized block design with one plot $(1.5$ by $10 \mathrm{~m})$ per cultivar. Growth stages (GS) were recorded following the decimal code (32). A disease rating scale of 1 to 9 was used to de- 
scribe the symptom severity on the uppermost three leaves on main tillers: $1=$ healthy, $2=20 \%$ leaf area with symptoms and so on, and $9=$ completely diseased. A specific scoring of the first leaves below the flag leaf (F-1) was also made because they were used for biochemical analyses. Field sampling was carried out as described previously (36). All biochemical and histochemical analyses were conducted with F-1 leaves on the main tillers unless otherwise stated.

Light shading treatment in the field. This experiment was conducted at the State Experimental Station for Agriculture in Gülzow, near Rostock, northeastern Germany, in 2001. At GS 32, $1 \mathrm{~m}^{2}$ in each plot of winter barley cvs. Anoa, Sarah, and Bombay was shaded with white cloth without specific wavelength absorbance. The shading reduced light intensity above the canopy from 72 to 75 klux to 22 to 23 klux on sunny days and from 16 to 5 klux on cloudy days, resulting in a light intensity reduction of about $70 \%$.

Induction of nonspecific necrosis in the greenhouse by ozone-light interaction. These experiments were conducted with spring barley cvs. Scarlett, Annabell, Extract, and Barke. According to the scoring results from the field, 'Scarlett' and 'Annabell' are insensitive to PLS, whereas 'Extract' and 'Barke' are susceptible. Plants were grown under standard greenhouse conditions at $20 / 14^{\circ} \mathrm{C}$ (day/night) and a 12 -h photoperiod per day (8 to $12 \mathrm{klux}$ ) until GS 30. The plants were then transferred to two fumigation chambers, one of which was installed with high-pressure sodium (HPS) lamps (SON-T AGRO, $400 \mathrm{~W}$; Philips, Eindhoven, the Netherlands) and another with metal halide (MH) lamps (HPI-T, $400 \mathrm{~W}$; Philips). The light intensity in both chambers was adjusted to 12 klux. The spectral energy distribution of the two light sources is shown in Figure 1, with $\mathrm{MH}$ exhibiting a spectrum stronger at short wavelengths than that of HPS. The chamber temperature was maintained at 20 to $22^{\circ} \mathrm{C}$ during ozone fumigation. Ozone was generated from pure oxygen by an electrical discharge generator (Fischer 500M, Meckenheim, Germany). Ozone concentrations were continuously measured with a UV-absorption detector (Dasibi 1008-AH, Glendale, USA). The concentrations were automatically monitored on a continuous 5-min cycle in each of the chambers, in the outlet of the chambers, and in ambient air. Plants were fumigated with 165 to $180 \mathrm{ppb}$ of ozone for 5 consecutive days ( $7 \mathrm{~h}$ /day). Leaf injury was recorded 2 days later as the symptoms readily developed.

A parallel experiment was conducted to test the ozone sensitivity of winter and spring barley genotypes. Nineteen winter barley cultivars and 11 spring barley cultivars were grown under standard greenhouse conditions as described previously until GS 13. Ozone fumigation was performed in the fumigation chambers described above. For winter barley, plants were exposed to ozone for 4 days $(7 \mathrm{~h} /$ day) with increasing ozone concentration to minimize the adaptation response of plants: $150 \mathrm{ppb}$ on day 1,160 to $180 \mathrm{ppb}$ on day 2, 185 to $190 \mathrm{ppb}$ on day 3, and 210 to $230 \mathrm{ppb}$ on day 4. For spring barley, plants were exposed to ozone for 3 days ( $7 \mathrm{~h}$ /day) with increasing ozone concentration: $150 \mathrm{ppb}$ on day 1,160 to $180 \mathrm{ppb}$ on day 2 , and 185 to $190 \mathrm{ppb}$ on day 3 . The temperature was maintained at $22^{\circ} \mathrm{C}$ with 8 klux light (HPS) during fumigation. Visible leaf injury was assessed 2 days after the end of fumigation as the symptoms readily developed.

Induction of leaf necrosis by light stress. Resistant spring barley cv. Scarlett and susceptible cvs. Extract and Barke were selected for necrosis inducing experiments. Seeds were sown in $10-\mathrm{cm}$ pots, two plants per pot. The plants were divided into two groups: one was grown under HPS lamps and the other under MH lamps. The light sources were the same as described previously (Fig. 1). The light intensity in both light regimes was maintained at 12 klux with a 12-h photoperiod and increased to a $16-\mathrm{h}$ photoperiod after the second leaf fully expanded. The growth temperature was 20 to $22^{\circ} \mathrm{C} / 16$ to $18^{\circ} \mathrm{C}$ (day/night). These plants were used for various light treatments as follows.
Light shock treatment. At GS 12 (second leaf fully expanded), some of the plants from both light sources were grown for 2, 4, 5, or 6 days under low light (400 to 800 lux), fluctuated according to daylight, at 20 to $22^{\circ} \mathrm{C} / 16$ to $18^{\circ} \mathrm{C}$ (day/night), and then transferred to normal growth conditions as described previously (12 klux HPS or $\mathrm{MH}, 20$ to $22^{\circ} \mathrm{C} / 16$ to $18^{\circ} \mathrm{C}$ [day/night]). In addition, some of the plants from the 4-day low light intensity treatment were exposed to 20 to $25 \mathrm{klux} \mathrm{MH}$, while some of the plants were kept growing on the low light intensity through all growth stages. The effects of these treatments on necrotic lesion formation were observed.

Continuous light treatment. At GS 13 (third leaf fully expanded and fourth leaf emerging), 14 plants each of 'Scarlett' and 'Extract' grown under HPS were treated with 12-klux continuous light at a constant temperature of 22 to $24^{\circ} \mathrm{C}$ for 7 days. Leaf necrosis was scored during and after the treatment.

Differentiation of wavelength spectrum. The other plants were kept growing under standard conditions as described previously under HPS or MH until maturity to investigate the effects of different wavelength spectrum on the induction of necrotic lesions. Severity of necroses and plant development were recorded regularly.

Biochemical measurement and histochemical localization of superoxide $\left(\mathrm{O}_{2}{ }^{-}\right)$and $\mathrm{H}_{2} \mathrm{O}_{2}$. Measurement of superoxide followed the modified method of $\mathrm{Wu}$ and von Tiedemann (36). Briefly, leaf disks (7 $\mathrm{mm}$ in diameter) were submerged in $500 \mu \mathrm{l}$ of $50 \mathrm{mM}$ phosphate buffer ( $\mathrm{pH} 7.8$ ) containing $1 \mathrm{mM}$ hydroxylammonium chloride and incubated for $30 \mathrm{~min}$ at room temperature. Then, $100 \mu \mathrm{l}$ of the incubation mixture was transferred into 96-well microtiter plates, adding $100 \mu \mathrm{l}$ of $17 \mathrm{mM}$ sulphanilamide (in $30 \%$ acetic acid) and $100 \mu \mathrm{l}$ of $7 \mathrm{mM} N$-(1-naphthyl)-ethylene diamine dihydrochloride, and incubated for $20 \mathrm{~min}$ at room temperature. The absorbance was measured at $540 \mathrm{~nm}$. To verify that $\mathrm{NO}_{2}^{-}$production was due to $\mathrm{O}_{2}^{--}$generated by the leaf disks, a control containing either superoxide dismutase (SOD) at $100 \mu \mathrm{g} \mathrm{ml}^{-1}$

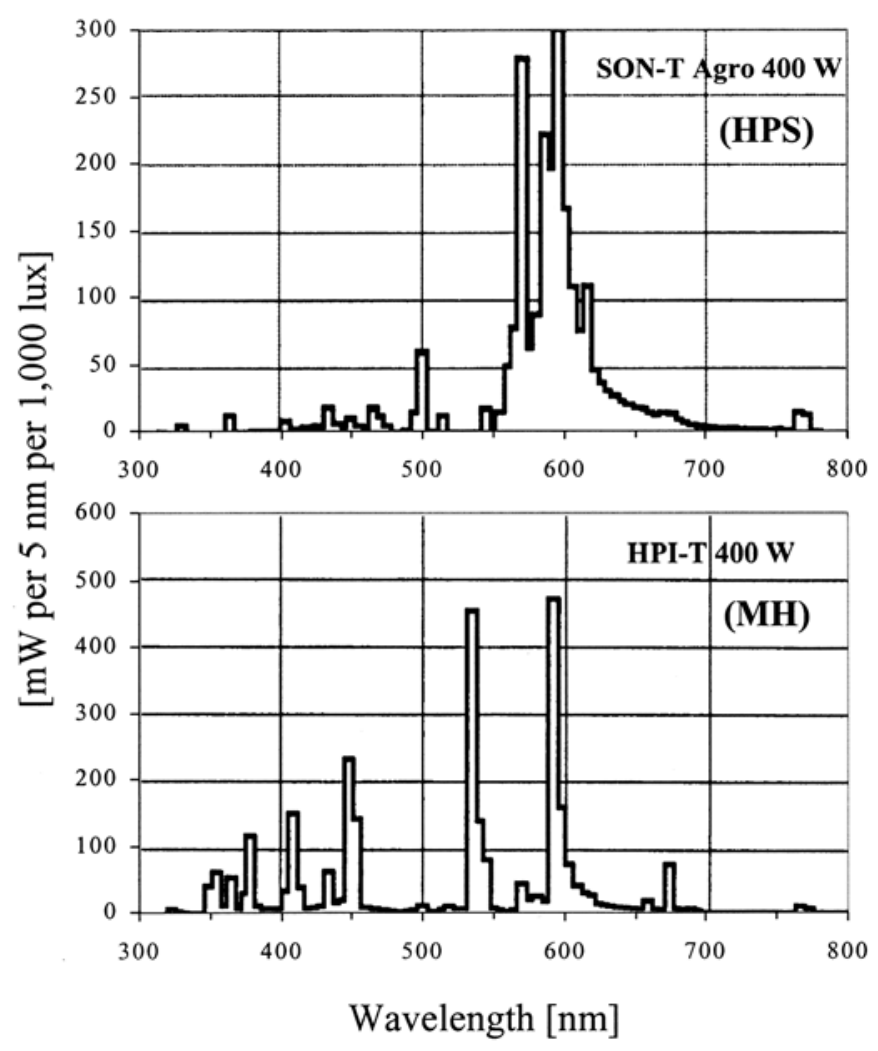

Fig. 1. Spectral energy distribution of high-pressure sodium (HPS) lamp (Philips SON-T Agro $400 \mathrm{~W}$ ) and metal halide (MH) lamp (Philips HPI-T $400 \mathrm{~W})$. 
or a reaction mixture without hydroxylamine was used. The hydrogen peroxide biochemical assay was the same as described previously (33).

The method for histochemical detection of $\mathrm{O}_{2}{ }^{-}$was based on the procedure described by Ádám et al. (1). Leaf disks were vacuum infiltrated with a solution containing $300 \mu \mathrm{M}$ nitroblue tetrazolium (NBT), $10 \mathrm{mM} \mathrm{NaN}_{3}$, and $0.1 \mathrm{mM}$ EDTA. After $8 \mathrm{~h}$ of incubation, leaf disks were cleared of pigments in a solution of methanol/acetic acid (3:1) and examined under the light microscope.

Antioxidant enzyme measurement. Leaves were harvested, snap-frozen in liquid nitrogen, and stored at $-85^{\circ} \mathrm{C}$. Frozen leaf tissue $(0.1$ to $0.15 \mathrm{~g})$ was homogenized in $2 \mathrm{ml}$ of cooled $\left(4^{\circ} \mathrm{C}\right)$ $50 \mathrm{mM}$ sodium phosphate buffer $(\mathrm{pH} 7.8)$ containing $0.1 \mathrm{mM}$ EDTA and 1\% (wt/wt) PVPP. For the ascorbate peroxidase activity assay, $5 \mathrm{mM}$ ascorbic acid was added to the extraction medium. The homogenate was centrifuged at $19,000 \times g$ for $30 \mathrm{~min}$. Aliquots of supernatants were used for protein determination or measured for enzyme activities. All assays were performed using a final volume of $1 \mathrm{ml}$, with at least duplicate assays undertaken on each sample. Enzyme activities were corrected for nonenzymatic rates and for interfering oxidation.
Total SOD activity was assayed according to the method of Elstner et al. (11), but modified by using xanthine/xanthine oxidase as $\mathrm{O}_{2}{ }^{--}$generation system. $\mathrm{Cu} / \mathrm{Zn}$-SOD (cyanide-sensitive) and $\mathrm{Fe}$ - or Mn-SOD (cyanide-insensitive) were differentiated in all samples by running the assay with or without $\mathrm{KCN}(2 \mathrm{mM})$ in the reaction mixture. $\mathrm{KCN}$ does not interfere with the assay system used. The color reaction was the same as in the $\mathrm{O}_{2}{ }^{--}$measurement. One enzyme unit is defined as $50 \%$ inhibition of the colorimetric reaction.

Ascorbate peroxidase activity was determined from the decrease in absorbance at $290 \mathrm{~nm}$ following the consumption of ascorbic acid (25). The assay contained $66 \mathrm{mM}$ phosphate buffer (pH 7.0), $2 \mathrm{mM} \mathrm{H}_{2} \mathrm{O}_{2}, 750 \mu \mathrm{M}$ ascorbic acid, and $100 \mu \mathrm{l}$ of extract. Ascorbate peroxidase activity was calculated using an extinction coefficient of $2.8 \mathrm{mM}^{-1} \mathrm{~cm}^{-1}$ for ascorbic acid at $290 \mathrm{~nm}$.

Glutathione reductase activity was measured following the decrease in absorbance at $340 \mathrm{~nm}$ associated with the oxidation of NADPH (15). The assay contained $66 \mathrm{mM}$ phosphate buffer $(\mathrm{pH}$ 7.8), $150 \mu \mathrm{M}$ NADPH, $500 \mu \mathrm{M}$ oxidized glutathione, and $50 \mu \mathrm{l}$ of extract. An extinction coefficient of $6.22 \mathrm{mM}^{-1} \mathrm{~cm}^{-1}$ was used to calculate the activity.
A

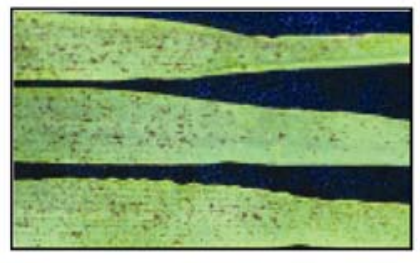

D

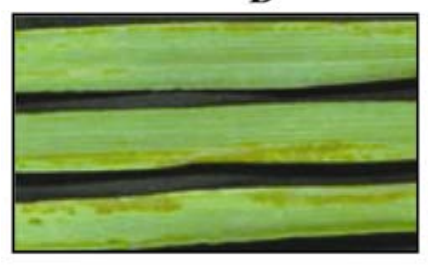

G

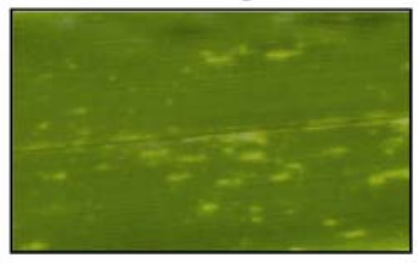

$\mathbf{J}$

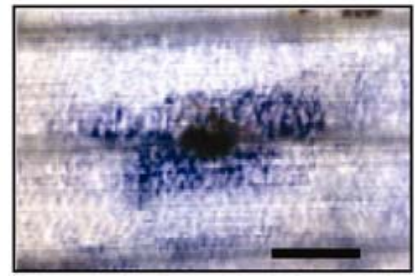

B

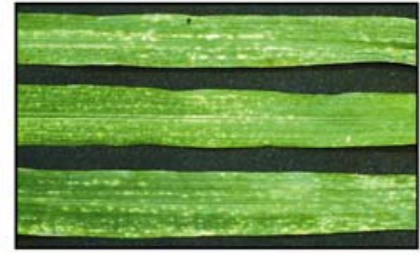

$\mathbf{E}$

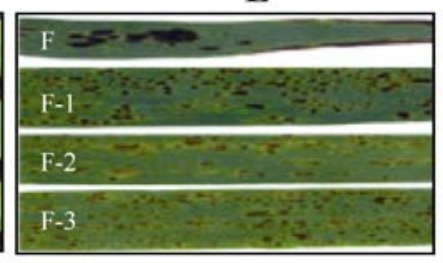

H

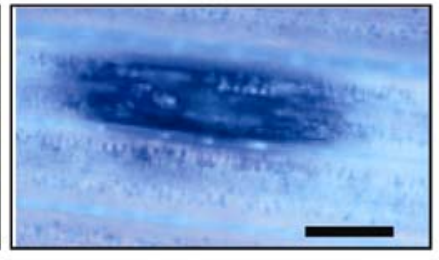

K

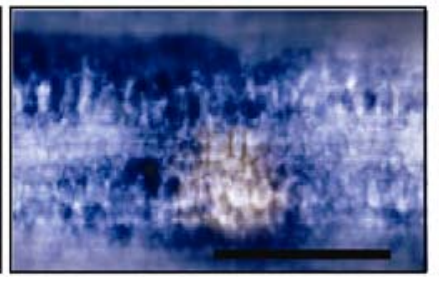

C

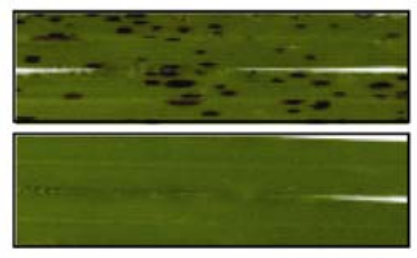

F

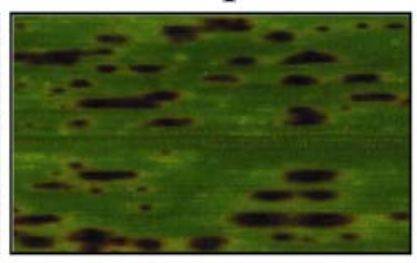

I

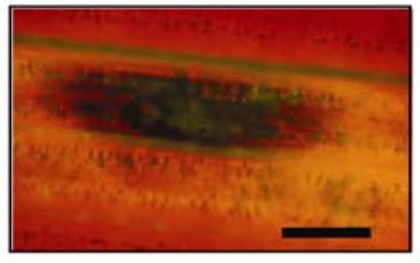

$\mathbf{L}$

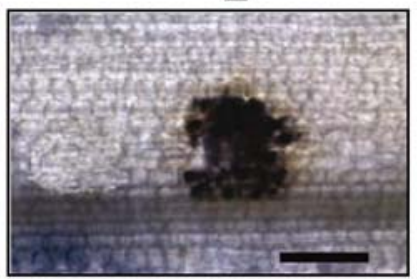

Fig. 2. Physiological leaf spot (PLS) symptoms expressed in the field and induced in the greenhouse, and $\mathrm{O}_{2}{ }^{--}$detection and autofluorescence in situ. A, PLS symptoms on cv. Extract in the field; B, PLS symptoms on cv. Extract induced by ozone; and C, PLS expression without shading (upper panel) and with partial shading from light (lower panel) on cv. Anoa under field conditions (growth stage 69). Anoa is one of the most PLS-sensitive winter barley cultivars (36). D, PLS symptoms on cv. Extract induced by continuous light treatment; E, PLS symptoms on cv. Extract induced by metal halide (MH) light in the greenhouse. F, F-1 represents flag leaf, the first leaf under the flag leaf and so on. Note expanded necrotic lesion on flag leaf (F). F and G, Enlarged necrotic lesions with chlorotic halos on 'Extract' and enlarged chlorotic spots on 'Barke' induced by light, respectively. $\mathbf{H}$ and I, Induced cell death on 'Extract' monitored by autofluorescence under UV-light excitation $(365 \mathrm{~nm})$ and under green light excitation $(546 \mathrm{~nm})$, respectively $(\mathrm{bar}=500 \mu \mathrm{m})$. $\mathbf{J}$, K, and $\mathbf{L}$, Induced lesions on 'Extract' with $\mathrm{O}_{2}{ }^{\circ-}-$ nitroblue tetrazolium (NBT) staining of whole lesions (J), with only the surrounding cells stained $(\mathbf{K})$ and with no staining of the lesion in dead tissue that is unable to produce $\mathrm{O}_{2}{ }^{-}(\mathbf{L})$, respectively $(\mathrm{bar}=500 \mu \mathrm{m})$. Stained leaf tissues were cleared of pigments in a solution containing methanol/acetic acid $(3: 1)$. NBT is reduced by $\mathrm{O}_{2}{ }^{-}$and forms bluish diformazane, which remains in a bound insoluble state within the cell. 
Dehydroascorbate reductase (DHAR) activity was determined from the increase in absorbance at $265 \mathrm{~nm}$ following the production of ascorbic acid (25). The assay contained $66 \mathrm{mM}$ phosphate buffer ( $\mathrm{pH}$ 6.5), $3 \mathrm{mM}$ reduced glutathione, $2.5 \mathrm{mM}$ dehydroascorbate (DHA), and $50 \mu \mathrm{l}$ of extract. DHAR activity was calculated using an extinction coefficient of $14 \mathrm{mM}^{-1} \mathrm{~cm}^{-1}$ for ascorbic acid at $265 \mathrm{~nm}$.

Monodehydroascorbate reductase (MDHAR) activity was determined following the oxidation of NADH at $340 \mathrm{~nm}$. Monodehydroascorbate (MDHA) was generated from ascorbic acid by ascorbate oxidase (AO). The assay contained $66 \mathrm{mM}$ phosphate buffer (pH 7.8), $150 \mu \mathrm{M}$ NADH, $500 \mathrm{mM}$ ascorbic acid, 0.2 units of $\mathrm{AO}$, and $50 \mu \mathrm{l}$ of extract (23). An extinction coefficient of $6.22 \mathrm{mM}^{-1} \mathrm{~cm}^{-1}$ for NADH at $340 \mathrm{~nm}$ was used to calculate MDHAR activity.

Total peroxidase activity was assayed following the modified method as described previously (36).

Lipid peroxidation was measured as the amount of malondialdehyde determined by the thiobarbituric acid reaction as described previously (36).

\section{RESULTS}

PLS symptom expression in the field. Under field conditions, PLS in winter and spring barley mostly affected the four uppermost leaves of sensitive cultivars. The symptoms initially are small chlorotic spots that later develop into necrotic lesions. On the same plants where the necrotic spots become visible on the lower leaves, upper leaves often show tiny chlorotic spots, which are assumed to be the initial symptoms of PLS. The shape and size of PLS varies among cultivars (Fig. 2A; 36).

Relationship between ozone resistance and PLS susceptibility in spring and winter barley. Two PLS-insensitive cultivars, 'Scarlett' and 'Annabell', showed significantly higher resistance to ozone than PLS-sensitive cvs. Barke and Extract (Table 1). MH light enhanced the damage caused by ozone, especially to younger leaves (fifth leaves). Ozone increased lipid peroxidation significantly $(P<0.05)$, with stronger response in 'Extract' and 'Barke' than of that in 'Scarlett' and 'Annabell' (Fig. 3). Correspondingly, lipid peroxidation was enhanced by $\mathrm{MH}$ light (Fig. 3).

A further investigation by enlarging the range of cultivars was performed. The cultivars included 19 winter barley and 11 spring barley cultivars. With this set of genotypes, no clear relationship could be established between ozone resistance and PLS sensitivity in winter barley, regarding the scoring results of PLS severity at GS 49/51 and GS 75 in both 1999 and 2000 (Fig. 4). However, ozone sensitivity of spring barley positively correlated

TABLE 1. Responses of different spring barley cultivars to ozone and the effects of light on ozone resistance (percent injured leaf area) ${ }^{\mathrm{w}}$

\begin{tabular}{lccl}
\hline Cultivar & Untreated & $\mathrm{O}_{3}+\mathrm{HPS}^{\mathrm{x}}$ & $\mathrm{O}_{3}+\mathrm{MH}^{\mathrm{y}}$ \\
\hline Fifth leaf $^{z}$ & & & \\
Scarlett & $0 \pm 0 \mathrm{a}$ & $1.8 \pm 1.2 \mathrm{~b}$ & $5.3 \pm 1.5 \mathrm{a}$ \\
Annabell & $0 \pm 0 \mathrm{a}$ & $0.8 \pm 2.0 \mathrm{a}$ & $5.2 \pm 2.9 \mathrm{a}$ \\
Extract & $0 \pm 0 \mathrm{a}$ & $3.5 \pm 2.3 \mathrm{c}$ & $5.8 \pm 2.0 \mathrm{ab}$ \\
Barke & $0 \pm 0 \mathrm{a}$ & $4.2 \pm 2.1 \mathrm{~cd}$ & $9.3 \pm 3.1 \mathrm{c}$ \\
Fourth leaf & & & \\
Scarlett & $0 \pm 0 \mathrm{a}$ & $16.7 \pm 4.1 \mathrm{a}$ & $23.3 \pm 8.2 \mathrm{ab}$ \\
Annabell & $0 \pm 0 \mathrm{a}$ & $15.0 \pm 4.5 \mathrm{a}$ & $16.7 \pm 4.1 \mathrm{a}$ \\
Extract & $0 \pm 0 \mathrm{a}$ & $30.8 \pm 5.8 \mathrm{~b}$ & $33.3 \pm 12.5 \mathrm{c}$ \\
Barke & $0 \pm 0 \mathrm{a}$ & $32.5 \pm 9.8 \mathrm{~b}$ & $34.2 \pm 10.3 \mathrm{c}$ \\
\hline
\end{tabular}

w Ozone fumigation: 165 to $180 \mathrm{ppb}$ ozone on 5 consecutive days ( $7 \mathrm{~h} /$ day) at growth stage 30 .

x Plants fumigated under light from high-pressure sodium lamps.

y Plants fumigated under light from metal halide lamps.

${ }^{\mathrm{z}}$ Leaves numbered in the order of emergence, first leaf is the oldest. Values are means \pm SE $(n=6)$. The letters after the data indicate significant differences at $P<0.01$, according to the least significant difference test, among the cultivars. with PLS severity at GS 55 in 1999 and at GS 75 in 2000 (Fig. 4). These results revealed that ozone is not likely to be the prime cause for PLS formation in barley. Furthermore, the lesions induced by ozone differed macroscopically from PLS symptoms as observed under field conditions (Fig. 2B).

Impact of light intensity on the induction of PLS expression in the field. PLS symptom expression was most predominant from GS 37/39 (flag leaf ligule visible) to GS 59/65 (ear emergence complete/half anthesis) under field conditions. Thus, light shading experiments, which realized about $70 \%$ reduction in light intensity, were conducted beginning at GS 32. Such treatments largely excluded PLS symptom expression in sensitive cultivars (Fig. 2C; Table 2), implying that high light intensity plays a prime role in PLS induction under field conditions.

Light shock effect. It has been reported that PLS occurred more prevalently when barley plants experienced sudden high irradiance in the field after an extended period of cloudiness (26). Therefore, we simulated such a light shock situation by growing plants under dim light conditions (400 to 800 lux) for 2, 4, 5, and 6 days, whereafter they were suddenly exposed to 12 klux HPS or $\mathrm{MH}$ light. In another experiment, plants were exposed to $25 \mathrm{klux}$ $\mathrm{MH}$ light after 4-day dim light treatment. All these measures failed to induce necrotic symptoms in both 'Scarlett' (resistant) and 'Extract' (sensitive), aside from general retarded growth by dim light treatment (data not shown).

Effects of continuous light and temperature on the formation of necrosis in barley. Treatment with continuous light and constant temperature did not induce any symptoms on insensitive cv. Scarlett, but did so on sensitive cv. Extract (Table 3). After 7 days of treatment, $43 \%$ of the 'Extract' plants showed tiny necrotic spots $(<1 \mathrm{~mm}$ in diameter $)$ on both the fourth and fifth leaves. Additionally, $50 \%$ of the plants showed expanded watersoaked lesions on fifth leaves (Fig. 2D). These lesions normally started from the edge of the leaves and became larger within a few days.

Effects of light quality on plant development. The responses of plant development to MH light were different between insensitive cv. Scarlett and sensitive cv. Extract. MH light enhanced the growth of 'Scarlett' but retarded the development of 'Extract' compared with that of plants grown under HPS light. Maturation was advanced by about 4 days in 'Scarlett' but delayed by about 6 days in 'Extract' when plants were grown under MH light compared to HPS light (data not shown).

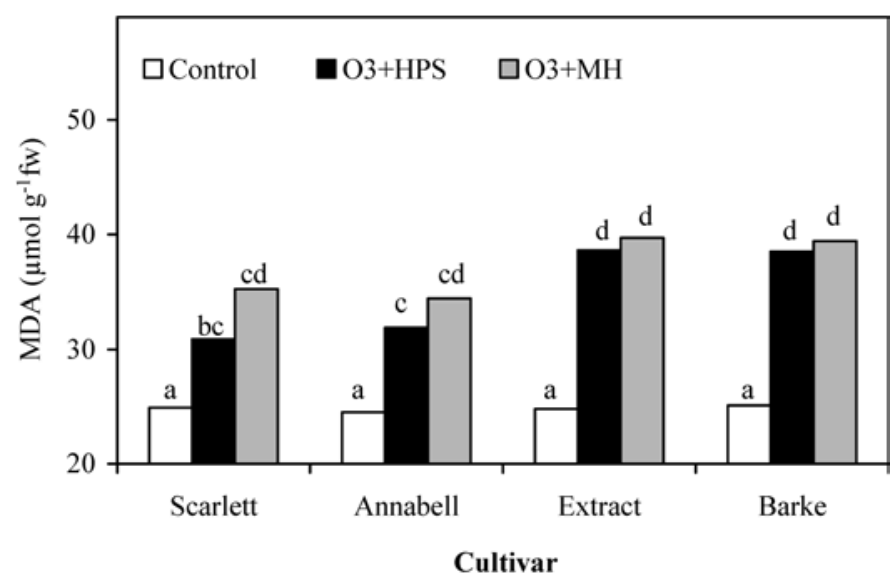

Fig. 3. Effect of ozone on lipid peroxidation (malondialdehyde [MDA]). Control indicates plants grown under standard greenhouse conditions. Ozone fumigation was 165 to $180 \mathrm{ppb}$ ozone for 5 consecutive days $(7 \mathrm{~h} /$ day $) .+$ HPS indicates plants fumigated under high-pressure sodium light and $+\mathrm{MH}$ indicates plants fumigated under metal halide light. MDA in the F-1 leaf extracts was measured by the thiobarbituric acid reaction. The letters above the columns indicate significant differences at $P<0.01$ (least significant difference). 
Effects of light quality on formation of leaf necroses. 'Scarlett' did not show any necrotic symptoms when grown under either light conditions (data not shown), whereas 'Extract' developed necrotic symptoms similar to those observed in the field under both HPS and MH light (Fig. 2E). The symptom development started from the lower leaf positions (Table 4) and was dependent on growth stage. The most predominant period of necrotic spot formation was from GS 39 to GS 55/59, very similar to the field observations.

Furthermore, light quality also affected symptom expression in 'Extract'. The development of necroses seemed to be chronic under HPS light. Chlorotic symptoms appeared to be the initial symptom of necrotic spots. At early growth stages (e.g., GS 39), the symptoms from flag leaves to leaf F-4 gradually increased in severity from healthy to chlorotic to necrotic. The same occurred on a specific leaf position, such as leaf F-1, in which the percentage of chlorosis increased from 18.2 to $90.7 \%$ from GS 39 to GS $53 / 55$ and then decreased with increasing necroses. The percentage of chlorotic leaves decreased with the increase of spot severity also in F-2 leaves (Table 4). However, symptoms developed less (F-2 and F-3) or even stopped developing on F and F-1 later than GS 59.

Compared with the symptom development under HPS light, the symptoms under MH light appeared more acute. Chlorotic symptoms were not as prevalent as under HPS light. No chlorotic symptoms appeared on flag leaves or F-1 leaves. Additionally, expanded necrotic lesions developed on flag leaves and F-1 leaves (Fig. 2E; Table 4, indicated by +++ ), which may be related to the higher irradiation imposed on these leaves. Furthermore, the chlorotic halo around the necrotic spot was more obvious under
MH light (Fig. 2F). The symptom development also lasted longer (until GS 69) than under HPS light (Table 4). MH light induced acute necrotic cell death, which was in agreement with the enhancement of ozone injury by MH light (Fig. 3).

Another cultivar sensitive to PLS, 'Barke', developed strong chlorotic symptoms under both HPS and MH light (Fig. 2G), but these chlorotic symptoms did not develop further into necrotic spots.

Superoxide and $\mathrm{H}_{2} \mathrm{O}_{2}$ accumulation in leaf tissues with PLS of field-grown barley. Under field conditions, $\mathrm{O}_{2}{ }^{--}$production increased in parallel with PLS symptom development with progressing growth stage (36). $\mathrm{O}_{2}{ }^{--}$production and $\mathrm{H}_{2} \mathrm{O}_{2}$ accumulation in leaf tissues with severe PLS (7 to 9) were significantly higher than that of leaf tissues only slightly affected (1 to 3) (Fig. $5 ; P<0.01)$.

Superoxide production in necrotic leaf tissues induced in the greenhouse. Treatment with continuous light and constant temperature significantly enhanced the superoxide production $(P<$

TABLE 2. Effects of light intensity on physiological leaf spots (PLS) expression on winter barley grown in the field (Gülzow, NE Germany, 2001) ${ }^{\mathrm{z}}$

\begin{tabular}{lcc}
\hline Cultivar & Control & Shading \\
\hline Anoa & 4 & $1-2$ \\
Sarah & 3 & 1 \\
Bombay & 2 & 1 \\
\hline
\end{tabular}

${ }^{\mathrm{z}}$ Shading treatment was conducted at growth stage (GS) 32 and caused $70 \%$ reduction in light intensity above the canopy. Shading area was $1 \mathrm{~m}^{2}$ for each cultivar. PLS scoring was from 1 (healthy) to 9 (completely diseased), referring to F-1 leaves at GS 69.
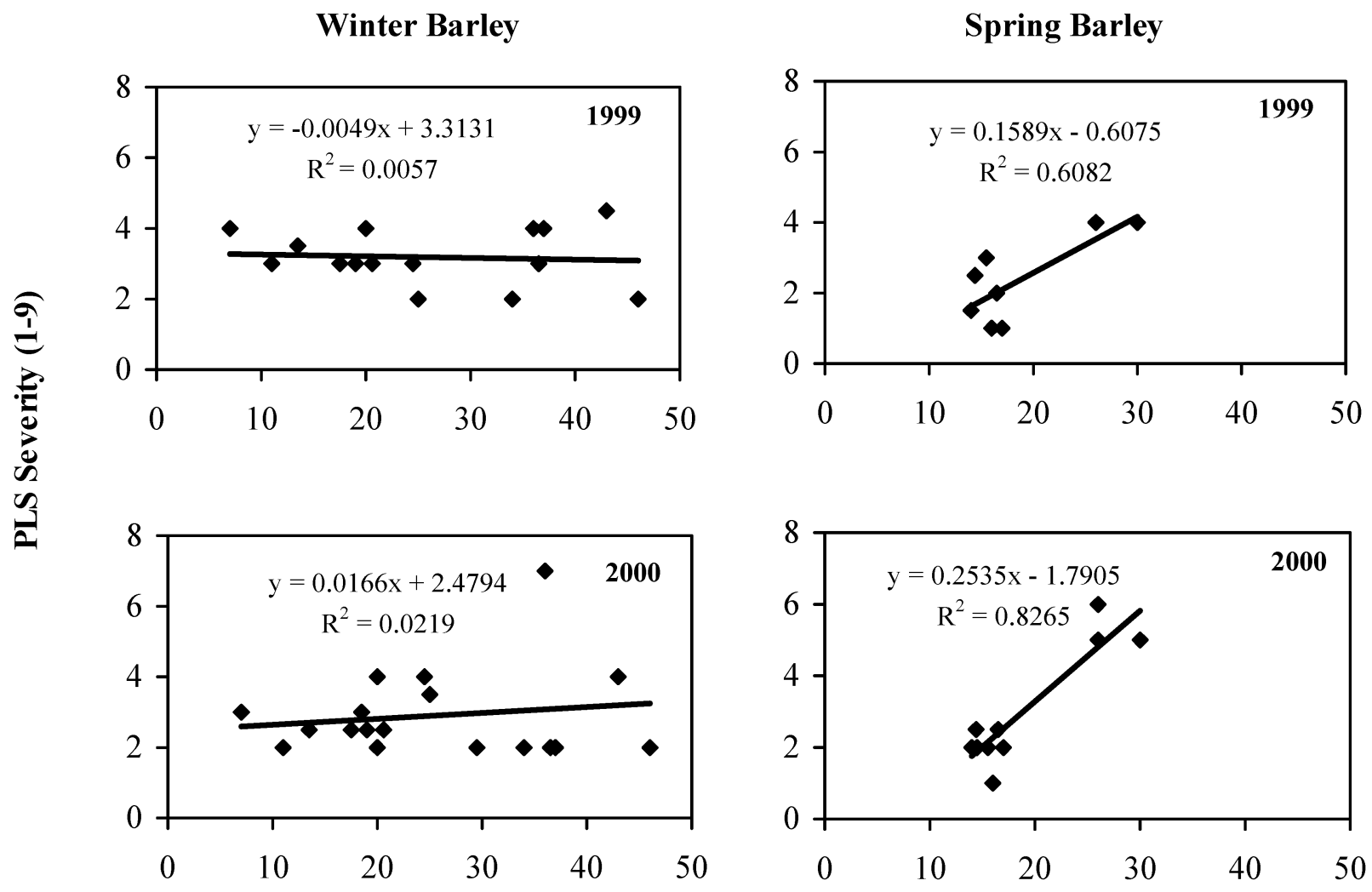

\section{Ozone Injury (\% leaf area)}

Fig. 4. Correlation between ozone resistance and physiological leaf spot (PLS) sensitivity of barley. Ozone fumigation for winter barley was 150 to 210 ppb for 4 days ( $7 \mathrm{~h}$ /day); and ozone fumigation for spring barley was 150 to $190 \mathrm{ppb}$ for 3 days (7 h/day). Visible ozone injury data were from second leaves, 10 plants for each cultivar. PLS severity scoring was performed in Biestow, Rostock, at growth stage (GS) 75 for winter barley in 1999 and 2000 ; PLS severity data for spring barley were from GS 55 in 1999 and from GS 75 in 2000. Data were from 19 winter barley cultivars and 11 spring barley cultivars. 
0.01) on both 'Scarlett' and 'Extract' (Fig. 6). However, this enhancement was more pronounced on sensitive cv. Extract $(P<$ 0.01). Superoxide levels in untreated plants were higher in 'Extract' than in 'Scarlett' $(P<0.01)$. This was in agreement with the results obtained under field conditions (36).

Histochemical localization of $\mathrm{O}_{2}{ }^{--}$in leaf tissue with induced PLS. Induced necrotic cell death could be detected by autofluorescence as shown in Figure $2 \mathrm{H}$ and $\mathrm{I} \mathrm{O}_{2}{ }^{-}$, as a potential contributor to the induced necrotic lesion formation in the greenhouse, could be directly detected and traced by NBT staining. Similar to the results from the field, there were three kinds of responses to NBT staining: starting spots completely stained (Fig. 2J), developing spots with only the surrounding cells stained (Fig. $2 \mathrm{~K}$ ), and no staining of the spots (Fig. 2L). We assume that these staining types represent stages in spot genesis from initial to developing PLS, with ample production of $\mathrm{O}_{2}{ }^{-}$, finally turning into dead tissue spots with ceasing $\mathrm{O}_{2}{ }^{--}$production of leaf cells involved.

Antioxidant enzymes and PLS. In chloroplasts, detoxification of $\mathrm{H}_{2} \mathrm{O}_{2}$ is mainly performed by ascorbate-specific peroxidase. Together with glutathione reductase, DHAR, and MDHAR, it is thought to remove $\mathrm{H}_{2} \mathrm{O}_{2}$ through a mechanism termed the Halliwell-Asada cycle. The activities of the major enzymes of the Halliwell-Asada cycle were significantly lower $(P<0.01)$ in aged leaves (F-1) with more severe PLS symptoms than in younger leaves (flag leaf) with less severe symptoms (Table 5). However, the activity of peroxidase, often associated with tissue browning and necrosis in response to various environmental stresses (10), was significantly higher in severely affected leaves $(P<0.01)$ (Fig. 5; Table 5).

Total SOD activities were not significantly different between 'Scarlett' and 'Extract', but $\mathrm{Cu} / \mathrm{Zn}$-SOD activities were significantly higher in 'Scarlett' than in 'Extract'. However, 'Extract' showed a significantly higher level of Fe-SOD activity (Table 6).

TABLE 3. Induction of leaf lesions in spring barley (percentage of plants expressing symptoms) exposed to continuous light at constant temperature ${ }^{\mathrm{z}}$

\begin{tabular}{lcccccc}
\hline & \multicolumn{2}{c}{ Tiny necrotic spots $(\varnothing<1 \mathrm{~mm})$} & & \multicolumn{2}{c}{ Water soaked-like lesion } \\
\cline { 2 - 3 } Cultivar & Fourth leaf & Fifth leaf & & Fourth leaf & Fifth leaf \\
\hline Extract & 43 & 43 & & 0 & 50 \\
Scarlett & 0 & 0 & & 0 & 0 \\
\hline
\end{tabular}

z Plants were grown under continuous light (12 klux; high-pressure sodium lamps) and constant temperature $\left(22\right.$ to $\left.24^{\circ} \mathrm{C}\right)$ started at growth stage 13 for 7 days and symptoms were recorded. The total number of treated plants for each cultivar was 14 .
This enzyme is specifically localized in chloroplasts, implying that antioxidant capacity balanced between specific and critical subcellular compartments may be crucial in targeting oxidative stress.

\section{DISCUSSION}

Ozone is an important phytotoxic air pollutant and may cause "water-logging," "bronzing," and "flecking" leaf injury symptoms (18). Thus, it appears reasonable to link the etiology of PLS symptoms in barley to the impact of ozone. However, from the data, ozone can be excluded as the sole cause of PLS for several reasons: (i) The macroscopic symptoms of ozone injury are different from the PLS symptoms observed in the field and in the greenhouse, and (ii) there was no correlation in winter barley genotypes regarding ozone sensitivity and PLS susceptibility. Although a relatively high correlation of PLS sensitivity with ozone resistance was established in spring barley, this does not necessarily document ozone as the single cause of PLS. Also (iii), only after exposure to relatively high concentrations of the pollutant did plants show visible injury symptoms. In our study, winter and spring barley were highly resistant to ozone. Symptoms were only visible at concentrations of 150 to $210 \mathrm{ppb}$ and exposure for 4 days on winter barley and 150 to $190 \mathrm{ppb}$ for 3 days on spring barley. These are levels that occur quite rarely in field sites in Europe (17). Furthermore, background ozone concentration in the filtered greenhouse air was only 5 to $12 \mathrm{ppb}$ from October through March; however, PLS symptoms occurred under such greenhouse conditions. Such a low concentration is unlikely to cause visible symptoms. Nonetheless, we still do not exclude ozone as a participant in the multiple complex of inducing factors.

Some plant species develop distinct injury symptoms when grown under continuous light in combination with constant temperature. Tomato and potato have been studied extensively $(5,8$, 20). Injury symptoms appeared as brown necrotic spots on the adaxial leaf surface and as an interveinal chlorosis only on young, expanding leaves at the apex of the plants $(3,8)$. No similar study has been hitherto made about continuous light as an inducer of chlorosis and necrosis in cereal leaves. Our results demonstrate that continuous light also induced necrotic symptoms in barley plants. The symptom characteristics, chronological appearance of the symptoms ( 5 to 12 days after the beginning of the continuous light period), and differential responses of cultivars (sensitive and insensitive) were similar to those observed in tomato and potato $(5,8,20)$. Our study indicates that PLS-sensitive 'Extract' responded to continuous light stress quite different from that of in-

TABLE 4. Effects of different light sources on expression of leaf lesions on different leaf positions of spring barley cv. Extract

\begin{tabular}{|c|c|c|c|c|c|c|c|c|c|c|c|}
\hline \multirow[b]{3}{*}{ Light source ${ }^{\mathrm{x}}$} & \multirow[b]{3}{*}{ Leaf position ${ }^{y}$} & \multicolumn{10}{|c|}{ Duration of treatment, growth stage $(\mathrm{GS})^{\mathrm{z}}$} \\
\hline & & \multicolumn{2}{|c|}{50 days, GS 39} & \multicolumn{2}{|c|}{56 days, GS 49/51 } & \multicolumn{2}{|c|}{63 days, GS 53/55 } & \multicolumn{2}{|c|}{69 days, GS 59} & \multicolumn{2}{|c|}{79 days, GS 69} \\
\hline & & CS $(\%)$ & NS & CS $(\%)$ & NS & $\mathrm{CS}(\%)$ & NS & CS (\%) & NS & CS $(\%)$ & NS \\
\hline \multicolumn{12}{|l|}{ HPS } \\
\hline & $\mathrm{F}$ & 0 & 0 & 0 & 0 & 6.9 & + & 27.9 & + & 27.9 & + \\
\hline & F-1 & 18.2 & 0 & 65.9 & 0 & 90.7 & 0 & 67.4 & + & 67.4 & + \\
\hline & $\mathrm{F}-2$ & 81.8 & + & 18.2 & + & 4.7 & + & 0 & ++ & 0 & ++ \\
\hline & $\mathrm{F}-3$ & 0 & + & 0 & + & 0 & ++ & 0 & ++ & 0 & ++ \\
\hline & F-4 & 0 & + & 0 & ++ & 0 & ++ & 0 & ++ & 0 & ++ \\
\hline \multicolumn{12}{|l|}{ MH } \\
\hline & $\mathrm{F}$ & 0 & 0 & 0 & 0 & 0 & +++ & 0 & +++ & 0 & +++ \\
\hline & F-1 & 0 & 0 & 0 & 0 & 0 & +++ & 0 & +++ & 0 & +++ \\
\hline & F-2 & 20.5 & 0 & 38.6 & 0 & 46.2 & +++ & 0 & +++ & 0 & +++ \\
\hline & F-3 & 18.2 & ++ & 0 & ++ & 0 & + & 0 & ++ & 0 & ++ \\
\hline & F-4 & 31.8 & ++ & 11.4 & ++ & 0 & ++ & 0 & ++ & 0 & ++ \\
\hline
\end{tabular}

${ }^{\mathrm{x}}$ HPS = high-pressure sodium light; and MH = metal halide light (Fig. 1).

${ }^{\text {y }} \mathrm{F}=$ flag leaf; F-1 = the first leaf below the flag leaf and so on.

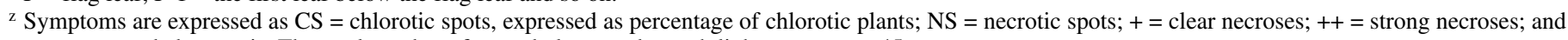
$+++=$ expanded necrosis. The total number of scored plants under each light source was 45 . 
sensitive cv. Scarlett. Furthermore, the different responses to continuous light stress between 'Scarlett' and 'Extract' were directly proportional to the superoxide production, implying reactive oxygen species (ROS) to be involved in continuous light-induced injuries.

Interestingly, continuous light injury symptoms in potato plants only appeared on the target leaflet when it was about 5 to $10 \mathrm{~mm}$ long at the time the continuous light period began (8). The original leaves we targeted were the fourth leaf at 3 to $5 \mathrm{~cm}$ long when we started the treatment with constant light and temperature. However, these original target leaves only showed tiny necrotic spots. In contrast, the fifth leaf, which developed only during the
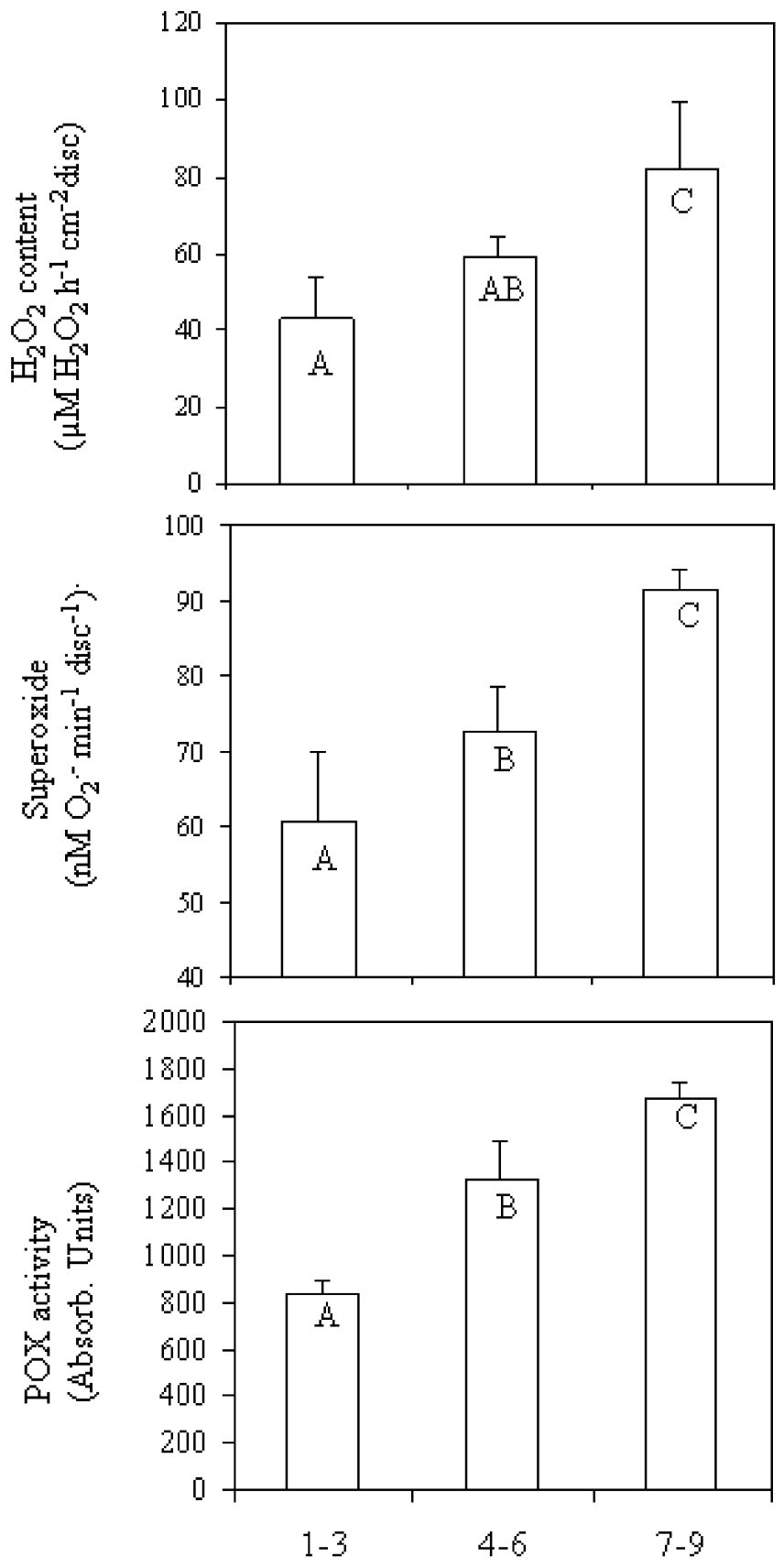

PLS symptom grade

Fig. 5. $\mathrm{H}_{2} \mathrm{O}_{2}$ content, $\mathrm{O}_{2}{ }^{--}$production, and peroxidase activity in $\mathrm{F}-1$ leaves of spring barley (cv. Barke) related to physiological leaf spot (PLS) symptom grade grown in field (Biestow, Rostock 2000). Samples were taken at growth stage 75 . Values are means $\pm \operatorname{SE}(n=6)$. Letters in the columns indicate significant differences at $P<0.01$ (least significant difference). treatment, displayed large necrotic lesions, revealing that only tissue of specific physiological age is injured by continuous light stress. This might explain why PLS only occurred on certain leaf positions and parts of the leaves.

A fast change in light intensity, from low to high, often enhances photooxidation of chlorophyll. Indeed, under field condition, PLS incidence became more predominant as barley plants encountered a period of low radiation following high radiation episodes (26). However, we did not observe this effect under greenhouse conditions when plants were grown under dim light (400 to 800 lux) for various days followed by exposure to high light intensity of 12 to 25 klux, although the growth of plants was obviously retarded by dim light treatment for 4 or 6 days. Chlorophyll content of rye seedlings grown under low light intensity (10 lux) increased even after exposure to high intensity light (30 klux). However, this light intensity shift did enhance the photodestruction of chlorophyll on rye leaves treated with chlorosisinducing herbicides (13). These results imply that light intensity shifts may play a role as a cofactor in chlorosis-inducing effects only when other inducing factors preexist. In the same experiment, Feierabend and Winkelhüsener (13) found that the enhancement of photooxidation of chlorophyll by high light intensity under the influence of chlorosis-inducing herbicides could be inhibited by scavengers of $\operatorname{ROS}\left(\mathrm{O}_{2}{ }^{1}, \mathrm{H}_{2} \mathrm{O}_{2}\right.$, and $\left.\mathrm{O}_{2}{ }^{--}\right)$, implying that these oxyradicals are involved in light-induced leaf chlorosis. The enhancement of leaf chlorosis and necrosis by high light intensity under $\mathrm{Zn}$-, Mn-, and K-deficiency was also related to ROS metabolism (4). Sensitive cv. Extract did not express necrotic lesions under dim light in the greenhouse, and under field conditions, a $70 \%$ shading of barley plants strongly retarded the PLS incidence (Table 2; Fig. 2C), suggesting that high light intensity is essential to induce the expression of symptoms. However, we remain unconvinced as to whether light is a primary factor in inducing the abiotic necroses or whether it acts by influencing other physiological processes.

Light is the predominant factor that provides plants with both energy and signal information from the environment. Significantly different ontogenetic responses to light quality were found between cultivars sensitive or resistant to PLS. MH light slightly accelerated the ontogenetic development of 'Scarlett', but delayed the development of 'Extract'. These different responses to light between PLS-sensitive and -resistant cultivars further suggest that

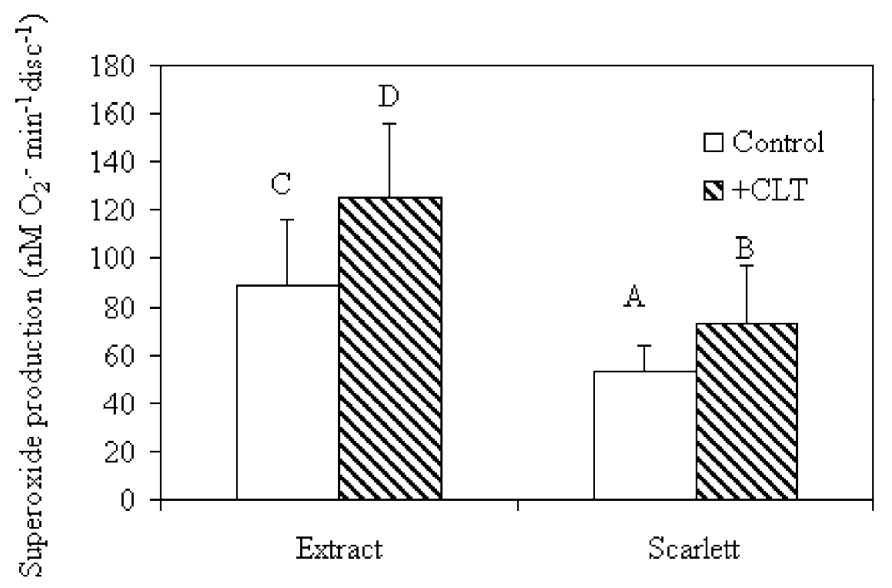

\section{Cultivar}

Fig. 6. Effects of continuous light (+CLT) with constant temperature on superoxide production of spring barley. Plants were grown under continuous light (12 klux) and constant temperature $\left(22\right.$ to $\left.24^{\circ} \mathrm{C}\right)$ for 7 days. Samples were derived from the fifth leaves. Values are means $\pm \operatorname{SE}(n=6)$. The letters above the columns indicate significant differences at $P<0.01$ (least significant difference). 
genetic variation is important in the determination of the response to PLS inducing environmental signals. Light quality also affected the necrotic lesion development of 'Extract'. MH light induced more acute and larger necrotic lesions on upper leaves. Compared with HPS light, the proportion of short wavelengths from 350 to $560 \mathrm{~nm}$ is much higher in $\mathrm{MH}$ (Fig. 1), and this part of the spectrum is closely related to plant morphology (termed morphologically active radiation, 300 to $500 \mathrm{~nm}, 700$ to $750 \mathrm{~nm}$ ). 'Extract' initially formed similar necrotic lesions but later displayed different lesion types under the two light sources (Table 4 ), indicating that $\mathrm{MH}$ light with shorter wavelength components may affect the expanding phase of lesion formation but not its initiation. This may explain why superoxide production was consistently related to symptom severity and is further confirmed by the fact that large necrotic lesions only appeared on the upper leaves which absorb more radiation.

Studies of wavelength effects on the lesion formation of the Sekiguchi lesion ( $s l$ ) mutant of rice (2) and the lethal leaf spot 1 (lls1) mutant of maize (7) revealed that the effective wavelength region for $s l$ formation is 400 to $700 \mathrm{~nm}$ and for $l l s 1$ is 650 to $700 \mathrm{~nm}$. This light region is similar to that for photosynthesis (photosynthetically active radiation, 400 to $700 \mathrm{~nm}$ ). Thus, Arase et al. (2) assumed that the possible photoreceptor for $s l$ lesion formation is in the chloroplasts. An alternative hypothesis proposed by Close et al. (7) is that photosynthetic activity may contribute to ROS generation leading to lesion initiation. Moch and Gimm (24) reported that high light intensity stimulates the formation of leaf necrosis in tobacco associated with the accumulation of uroporphyrin(ogen) leading to the generation of ROS. More recently, Fath et al. (12) reported that light, especially in the blue and UVA spectrum, accelerated cell death of gibberellic acid-treated barley aleurone cells, which was a result of elevated $\mathrm{H}_{2} \mathrm{O}_{2}$ content and lowered activities of ROS scavenging enzymes.

There is compelling evidence that ROS, such as superoxide and $\mathrm{H}_{2} \mathrm{O}_{2}$, are essential in initiating lesion formation and programmed cell death $(21,22,27)$. Our studies clearly showed that PLS formation in the field and induction in the greenhouse is related to ROS. The toxic accumulation of ROS may result from the impaired or reduced ROS scavenging potential in PLS-affected leaf tissue (36). Chloroplasts are the most important light sensing organelles as well as the main sources of ROS in higher plants, and thus continuously threatened through damages induced by the photooxidative stress $(6,16)$. Interestingly, in the present study, we found that sensitive cv. Extract showed a lower level of $\mathrm{Cu} / \mathrm{Zn}-\mathrm{SOD}$ activity but a higher level of chloroplast-specific Fe-SOD activity than that of insensitive cv. Scarlett. In contrast, the key enzymes in the Halliwell-Asada cycle were significantly lower in leaves severely affected with PLS. Thus, a higher level of chloroplastspecific SOD activity, which converts more superoxide into $\mathrm{H}_{2} \mathrm{O}_{2}$, but a lower level of enzymes in the Halliwell-Asada cycle, a main $\mathrm{H}_{2} \mathrm{O}_{2}$ scavenging system in chloroplasts, may have resulted in the accumulation of $\mathrm{H}_{2} \mathrm{O}_{2}$ in chloroplasts, which together with $\mathrm{O}_{2}{ }^{\cdot-}$ contributed to PLS formation. Therefore, chloroplasts might be critical cell compartments in triggering the PLS formation in barley. This is in agreement with the fact that light is an essential factor for PLS formation under both field and greenhouse conditions. At present, we still cannot identify which wavelengths are effective to PLS formation and its relationship to ROS. Many of the details have yet to be experimentally verified.

It is noteworthy that the responses to light are also different among the sensitive cultivars. Unlike 'Extract', under light stress conditions, sensitive cv. Barke displayed only strong chlorotic symptoms that did not further develop into necrotic spots, suggesting that the inducing conditions we used in this study were not strong enough to induce necrotic spot formation in this cultivar. This is in agreement with the results we observed in field conditions (36), in which the initial PLS symptom expression of 'Barke' occurred much later (GS 61) than that of 'Extract' (GS 39), but they achieved almost the same final level of symptom severity at GS 75, indicating that PLS symptom initiation is dependent on the severity of environmental stress factors during the main growth period.

To the best of our knowledge, this report is the first to demonstrate the reproduction of symptoms similar to PLS in the absence of pathogens in the greenhouse and confirms our previous findings under field conditions that PLS on barley are caused by a physiological disorder related to oxidative stress. The different responses to various inducing factors between PLS-sensitive and PLS-insensitive cultivars as well as among the sensitive cultivars reveals that the symptom expression has a distinct genetic basis. Indirect evidence supporting this point derives from our observations that spring barley cultivars containing the mlo gene were more susceptible to PLS (data not shown). It has been reported that necrotic lesions on mlo plants could be induced at low temperature in the absence of pathogens (9). More recently, Piffanelli et al. (28) found that transmembrane MLO protein functions in suppressing cell death under both biotic and abiotic stresses and mlo-enhanced cell death was related to $\mathrm{H}_{2} \mathrm{O}_{2}$ accumulation in the cell wall space. Hence, PLS is most likely a kind of nonspecific cell death determined by the genotype, but its expression needs to be primed by certain environmental factors, such as high light intensity. However, plants are simultaneously subjected to multiple environmental stresses such as high light irradiation, high temperature, air pollutants, nutrient deficiency, drought, and pathogens in the field. These factors or some of them may be coordinately involved in the formation of PLS. Thus, further studies are needed to determine whether and which single or multiple environment-genotype interactions induce the necrotic symptoms.

TABLE 6. Superoxide dismutase (SOD) activity in F-2 leaves of greenhousegrown spring barley with different sensitivity to physiological leaf spots (PLS) (units per gram of fresh weight) ${ }^{\mathrm{y}}$

\begin{tabular}{lccc}
\hline Cultivar & Total SOD & Fe- and Mn-SOD & Cu/Zn-SOD \\
\hline Scarlett & $2,828 \pm 28 \mathrm{ab}$ & $989 \pm 104 \mathrm{a}$ & $1,839 \pm 76 \mathrm{~b}$ \\
Extract & $2,708 \pm 41 \mathrm{a}$ & $1,185 \pm 66 \mathrm{~b}$ & $1,523 \pm 25 \mathrm{a}$ \\
\hline
\end{tabular}

${ }^{y}$ F-2 leaves were sampled from plants grown under high-pressure sodium light at growth stage 55 .

${ }^{\mathrm{z}} \mathrm{KCN}$ inhibition test was conducted by adding $\mathrm{KCN}$ to the reaction mixture at a final concentration of $2 \mathrm{mM}$. The measured SOD activity represented Fe-/Mn-SOD, the inhibited SOD represented $\mathrm{Cu} / \mathrm{Zn}-\mathrm{SOD}$ activities. Letters after data indicate significant differences within the same type of SOD at $P<0.05$ according to the least significant difference test $(n=3)$.

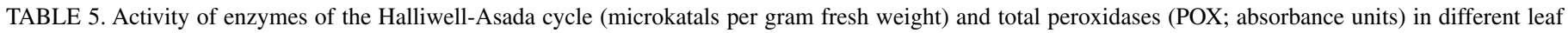
positions with different physiological leaf spot (PLS) severity of winter barley cv. Carola grown in the field ${ }^{\mathrm{x}}$

\begin{tabular}{|c|c|c|c|c|c|c|}
\hline Leaf $^{y}$ & $\mathrm{PLS}^{\mathrm{z}}$ & APX & GR & DHAR & MDHAR & POX \\
\hline$\overline{\text { Flag leaf }}$ & 3 & $157.7 \pm 5.4 \mathrm{a}$ & $53.4 \pm 4.7 \mathrm{a}$ & $87.3 \pm 1.1 \mathrm{a}$ & $88.4 \pm 4.5 \mathrm{a}$ & $1,067 \pm 88 \mathrm{a}$ \\
\hline $\mathrm{F}-1$ & 5 & $90.1 \pm 5.9 \mathrm{~b}$ & $17.7 \pm 2.4 b$ & $52.4 \pm 2.5 b$ & $42.6 \pm 4.5 b$ & $2,275 \pm 152 b$ \\
\hline
\end{tabular}

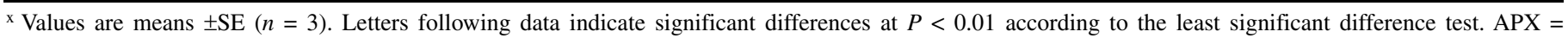
ascorbate peroxidase; $\mathrm{GR}=$ glutathione reductase; $\mathrm{DHAR}=$ dehydroascorbate reductase; and MDHAR = monodehydroascorbate reductase.

y Leaves were sampled from main tillers at GS 65/69 (1999, Rostock).

z PLS was assessed from 1 (healthy) to 9 (completely diseased). 


\section{ACKNOWLEDGMENTS}

We thank the State Experimental Station for Agriculture of Mecklenburg-Vorpommern (Biestow and Gülzow, Rostock) for conducting the cultivar evaluation experiments and I. Gliege for excellent technical assistance in the greenhouse.

\section{LITERATURE CITED}

1. Ádám, A., Farkas, T., Somlyai, G., Hevesi, M., and Király, Z. 1989. Consequence of $\mathrm{O}_{2}{ }^{--}$generation during a bacterially induced hypersensitive reaction in tobacco: Deterioration of membrane lipids. Physiol. Mol. Plant Pathol. 34:13-26.

2. Arase, S., Fukuyama, R., and Honda, Y. 2000. Light-dependent induction of Sekiguchi lesion formation by Bipolaris oryzae in rice cv. Sekiguchiasahi. J. Phytopathol. 148:193-196.

3. Brown, W. M. 1996. Physiological brown spot widespread in Pacific Northwest also found in San Luis Valley and along front range. Colo. State Univ. Coop. Ext. Pest Alert Newsl. 13:3.

4. Cakmak, I. 2000. Possible role of zinc in protecting plant cells from damage by reactive oxygen species. New Phytol. 146:185-205.

5. Cao, W., and Tibbitts, T. W. 1991. Physiological responses in potato plants under continuous irradiation. J. Am. Soc. Hortic. Sci. 116:525-527.

6. Casano, L. M., Gomez, L. D., Lascano, H. R., Gonzlaze, C. A., and Trippi, V. S. 1997. Inactivation and degradation of $\mathrm{Cu}, \mathrm{Zn}-\mathrm{SOD}$ by reactive oxygen species in wheat chloroplast exposed to photooxidative stress. Plant Cell Physiol. 38:433-440.

7. Close, P. S., Gray, J., and Johal, G. 1995. Observation of effect of light on the progression of lethal leaf-spot lesions. Maize Genet. Newsl. 69:48-49.

8. Cushman, K. E., Tibbitts, T. W., and Sharkey, T. D. 1995. Constant-light injury of potato: Temporal and spatial patterns of carbon dioxide assimilation, starch content, chloroplast integrity, and necrotic lesions. J. Am. Soc. Hortic. Sci. 120:1032-1040.

9. Dangl, J. L., Dietrich, R. A., and Richberg, M. H. 1996. Death don't have no mercy: Cell death programs in plant-microbe interactions. Plant Cell 8:1793-1807.

10. Elstner, E. F., and Osswald, W. 1994. Mechanisms of oxygen activation during plant stress. Proc. R. Soc. Edinb. 102B:131-154.

11. Elstner, E. F., Youngman, R. J., and Osswald, W. 1983. Superoxide dismutase. Pages 293-302 in: Methods of Enzymatic Analysis, vol. 3. H. U. Bergmeyer, ed., Verlag Chemie, Weinheim.

12. Fath, A., Bethke, P., Beligni, V., and Jones, R. 2002. Active oxygen and cell death in cereal aleurone cells. J. Exp. Bot. 53:1273-1282.

13. Feierabend, J., and Winkelhüsener, T. 1982. Nature of photooxidative events in leaves treated with chlorosis-inducing herbicides. Plant Physiol. 70:1277-1282.

14. Fowler, D. B. 1997. Leaf spots. Pages 2201-2245 in: Winter Wheat Production Manual. D. B. Folwer, ed. CPS Conservation Production System. Saskatoon, Saskatchewan.

15. Foyer, C. H., and Halliwell, B. 1976. The presence of glutathione and glutathione reductase in chloroplast: A proposed role in ascorbic acid metabolism. Planta 133:21-25.

16. Foyer, C. H., Lelandais, M., and Kunert, K. J. 1994. Photooxidative stress in plants. Physiol. Plant 92:696-717.
17. Fuhrer, H., Skärby, L., and Ashmore, M. R. 1997. Critical levels for ozone effects on vegetation in Europe. Environ. Pollut. 97:91-106.

18. Heath, R. L. 1980. Initial events in injury to plant by air pollutants. Annu. Rev. Plant Physiol. 31:395-431.

19. Hill, A. C., Pack, M. R., Treshow, M., Downs, R. J., and Transtrum, L. G. 1961. Plant injury induced by ozone. Phytopathology 51:356-363.

20. Hillman, W. S. 1956. Injury of tomato plants by continuous light and unfavorable photoperiodic cycles. Am. J. Bot. 43:89-96.

21. Jabs, T., Dietrich, R. A., and Dangl, J. L. 1996. Initiation of runaway cell death in an Arabidopsis mutant by extracellular superoxide. Science 273:1853-1856.

22. Jones, A. M., and Dangl, J. L. 1996. Logjam at the styx: Programmed cell death in plants. Trends Plant Sci. 1:114-119.

23. Lyons, T., Ollerenshaw, J. A., and Barnes, J. D. 1999. Impacts of ozone on Plantago major: Apoplastic and symplastic antioxidant status. New Phytol. 141:253-263.

24. Moch, H. P., and Gimm, B. 1997. Reduction of uroporphyrinogen decarboxylase by antisense RNA expression affects activities of other enzymes involved in tetrapyrrole biosynthesis and leads to light-dependent necrosis. Plant Physiol. 113:1101-1112.

25. Nakano, Y., and Asada, K. 1981. Hydrogen peroxide is scavenged by ascorbate-specific peroxidase in spinach chloroplasts. Plant Cell Physiol. 22:867-880.

26. Obst, A., Baumer, M., and Huber, G. 1995. Leaf blotch of nonparasitic origin on barley-Does the damaging occurrence increase? Gesunde Pflanze 47:308-314.

27. Panavas, T., and Rubinstein, B. 1998. Oxidative events during programmed cell death of daylily (Hemerocallis hybrid) petals. Plant Sci. 133:125-138.

28. Piffanelli, P., Zhou, F., Casais, C., Orme, J., Jarosch, B., Schaffrath, U., Collins, N., Panstruga, R., and Schulze-Lefert, P. 2002. The barley MLO modulator of defense and cell death is responsible to biotic and abiotic stress stimuli. Plant Physiol. 129:1076-1085.

29. Sachs, V. E., Amelung, D., and Klappach, K. 1998. The symptom of net blotch on barley, caused by Drechslera teres, and risks for diagnostic mistakes. Nachrbl. Dtsch. Pflanzenschutz. 50:58-63.

30. Smiley, R. W., Gillespie-Sasse, L.-M., Uddin, W., Collins, H. P., and Stroltz, M. A. 1993. Physiologic leaf spot of winter wheat. Plant Dis. 77:521-527.

31. Sutherland, K. G., and Lennard, J. H. 1988. Necrotic spotting on barley leaves associated with Erysiphe graminis and other factors. Crop Res. 28:49-65.

32. Tottman, D. R., and Broad, H. 1987. The decimal code for the growth stages of cereals, with illustrations. Ann. Appl. Biol. 110:441-454.

33. von Tiedemann, A. 1997. Evidence for a primary role of active oxygen species in induction of host cell death during infection of bean leaves with Botrytis cinerea. Physiol. Mol. Plant Pathol. 50:151-166.

34. von Tiedemann, A., and Wu, Y. X. 2001. Sauerstoffstress in Blättern. DLG-Mitteilungen 2:40-42.

35. Wolf, T. K., and Warren, M. K. 1995. Shoot growth rate and density affect bud necrosis of "Riesling" grapevines. J. Am. Soc. Hortic. Sci. 120:989996.

36. Wu, Y.-X., and von Tiedemann, A. 2002. Evidence for oxidative stress involved in physiological leaf spot formation in winter and spring barley. Phytopathology 92:145-155. 